\title{
EXPERIMENTAL INVESTIGATION ON EXHAUST EMISSIONS WITH CERAMIC COATED DIESEL ENGINE USING LINSEED OIL BASED BIODIESEL
}

\author{
S. Narasimha kumar ${ }^{1}$ \\ ${ }^{I}$ Mechanical Engineering Department, Chaitanya Bharathi Institute of Technology, Gandipet, Hyderabad, India
}

\begin{abstract}
Experiments were conducted to determine exhaust emissions in a conventional diesel engine (CE) and ceramic coated low heat rejection (LHR) diesel engine [with ceramic coated cylinder head] with different operating conditions [normal temperature and preheated temperature] of linseed oil based biodiesel with varied injection timing and injector opening pressure. Exhaust emissions [smoke and oxides of nitrogen]. Smoke levels decreased and NOx levels increased with engine with LHR combustion chamber with biodiesel operation. Advanced injection timing, increase of injector opening pressure preheated biodiesel reduced exhaust emissions from LHR engine with biodiesel operation.
\end{abstract}

Keywords: Alternate Fuels, Vegetable Oils, Biodiesel, LHR engine, Exhaust emissions, Combustion characteristics.

\section{INTRODUCTION}

The paper is divided into i) Introduction, ii) Materials and Methods, iii)Results and Discussions, iv) Conclusions, Future scope of work, v) Acknowledgements followed by References. Introduction deals with investigations carried out by researchers in the work related to the authors or brief literature review.

This section deals with need for alternate fuels in diesel engine, problems with use of crude vegetable oil in diesel engine, advantages of use of preheated vegetable oil in diesel engine, use of biodiesel in diesel engine, effect of increase of injector opening pressure and advanced injection timing on the performance of the diesel engine, concept of engine with LHR combustion chamber, advantages of LHR combustion chamber, classification of engines with LHR combustion chamber, use of diesel, crude vegetable oil and biodiesel in engine with LHR combustion chamber, research gaps and objectives of the investigations.

The world is presently confronted with the twin crises of fossil fuel depletion and environmental degradation. The fuels of bio origin can provide a feasible solution of this worldwide petroleum crisis(1-2).

It has been found that the vegetable oils are promising substitute, because of their properties are similar to those of diesel fuel and they are renewable and can be easily produced. Rudolph Diesel, the inventor of the diesel engine that bears his name, experimented with fuels ranging from powdered coal to peanut oil. Several researchers [3-6] experimented the use of vegetable oils as fuel on diesel engine and reported that the performance was poor, citing the problems of high viscosity, low volatility and their polyunsaturated character. The different fatty acids present [6] in the vegetable oil are palmic, steric, lingoceric, oleic, linoleic and fatty acids. These fatty acids increase smoke emissions and also lead to incomplete combustion due to improper air-fuel mixing. Experiments were conducted [7-10] on preheated vegetable [temperature at which viscosity of the vegetable oils were matched to that of diesel fuel] oils and it was reported that preheated vegetable oils improved the performance marginally and decreased pollution levels of smoke and NOx emissions. The problems of crude vegetable oils can be solved, if these oils are chemically modified to bio-diesel.

Bio-diesels derived from vegetable oils present a very promising alternative to diesel fuel since biodiesels have numerous advantages compared to fossil fuels as they are renewable, biodegradable, provide energy security and foreign exchange savings besides addressing environmental concerns and socio-economic issues. Experiments were carried out [1115] with bio-diesel on direct injection diesel engine and it was reported that performance was compatible with pure diesel operation on conventional engine. However biodiesel operation increased NOx levels.

Few investigators [16-19] reported that injector opening pressure has a significance effect [20] on the performance and formation of pollutants inside the direct injection diesel engine combustion. 
The other important engine variable to improve the performance of the engine is injection timing. Investigations were carried out [21-24] on single cylinder water cooled vertical diesel engine with brake power $3.68 \mathrm{~kW}$ at a speed of $1500 \mathrm{rpm}$ with varied injection timing from $27-34^{\circ} \mathrm{bTDC}$ and it was reported that performance of the engine improved with advanced injection timing and increased NOx emissions and decreased smoke levels.

The drawbacks associated with biodiesel for use in diesel engine call for low heat rejection (LHR) diesel engine.

The concept of LHR engine is to reduce heat loss to coolant by providing thermal insulation in the path of heat flow to the coolant. Engines with LHR combustion chamber are classified depending on degree of insulation such as low grade, medium grade and high grade insulated engines. Several methods adopted for achieving low grade LHR combustion chamber are using ceramic coatings on piston, liner and cylinder head, while medium grade LHR engines provide an air gap in the piston and other components with low-thermal conductivity materials like superni, cast iron and mild steel etc. High grade LHR engine is the combination of low grade and medium grade engines.

Engine with LHR combustion chamber with ceramic coating of thickness in the range of 500 microns on the engine components with pure diesel operation [25-27] provided adequate insulation and improved brake specific fuel consumption (BSFC) in the range of 5-7\%. The investigations on low grade LHR combustion chamber consisting of ceramic coating on cylinder head were extended [28-30] to crude vegetable oil also and reported that ceramic coated LHR engines marginally improved brake thermal efficiency.

Little literature was available on comparative studies on exhaust emissions and combustion characteristics with conventional diesel engine and engine with ceramic coated LHR combustion chamber with different operating conditions of the biodiesel with varied engine parameters. Hence attempt was made in that direction.

Table.1. Properties of Test Fuels

\begin{tabular}{|l|c|c|c|c|}
\hline \multicolumn{1}{|c|}{ Property } & Units & Diesel & Biodiesel & ASTM D 6751-02 \\
\hline Carbon chain & -- & $\mathrm{C}_{8}-\mathrm{C}_{28}$ & $\mathrm{C}_{16}-\mathrm{C}_{24}$ & $\mathrm{C}_{12}-\mathrm{C}_{22}$ \\
\hline Cetane Number & & 55 & 55 & $48-70$ \\
\hline Density & $\mathrm{gm} / \mathrm{cc}$ & 0.84 & 0.87 & $0.87-0.89$ \\
\hline Bulk modulus @ 20Mpa & $\mathrm{Mpa}$ & 1475 & 1850 & $\mathrm{NA}$ \\
\hline Kinematic viscosity @ 40 ${ }^{\circ} \mathrm{C}$ & $\mathrm{cSt}$ & 2.25 & 4.5 & $1.9-6.0$ \\
\hline Sulfur & $\%$ & 0.25 & 0.0 & 0.05 \\
\hline Oxygen & $\%$ & 0.3 & 10 & 11 \\
\hline Air fuel ratio (stochiometric) & -- & 14.86 & 14.2 & 13.8 \\
\hline Lower calorific value & $\mathrm{kJ} / \mathrm{kg}$ & 42000 & 38000 & 37518 \\
\hline Flash point(Open cup) & ${ }^{\circ} \mathrm{C}$ & 66 & 180 & 130 \\
\hline Molecular weight & -- & 226 & 280 & 292 \\
\hline Preheated temperature & ${ }^{\circ} \mathrm{C}$ & -- & 60 & -- \\
\hline Colour & & Light yellow & Yellowish orange & --- \\
\hline
\end{tabular}


The test fuels used in the experimentation were pure diesel and linseed oil based biodiesel. The schematic diagram of the experimental setup with test fuels is shown in Figure 1. The specifications of the experimental engine are shown in Table-2. The combustion chamber consisted of a direct injection type with no special arrangement for swirling motion of air. The engine was connected to an electric dynamometer for measuring its brake power. Burette method was used for finding fuel consumption of the engine. Air-consumption of the engine was measured by an air-box method (Air box was provided with an orifice meter and U-tube water manometer). The naturally aspirated engine was provided with watercooling system in which inlet temperature of water was maintained at $80^{\circ} \mathrm{C}$ by adjusting the water flow rate. Engine oil was provided with a pressure feed system. No temperature control was incorporated, for measuring the lube oil temperature. Copper shims of suitable size were provided [so as to vary the length of plunger in pump barrel] in between the pump body and the engine frame, to vary the injection timing and its effect on the performance of the engine was studied, along with the change of injector opening pressure from 190 bar to 270 bar (in steps of 40 bar) using nozzle testing device. The maximum injector opening pressure was restricted to 270 bar due to practical difficulties involved. Exhaust gas temperature was measured with thermocouples made of iron and iron-constantan.

Table.2. Specifications of the Test Engine

\begin{tabular}{|l|l|}
\hline \multicolumn{1}{|c|}{ Description } & \multicolumn{1}{c|}{ Specification } \\
\hline Engine make and model & Kirloskar ( India) AV1 \\
\hline $\begin{array}{l}\text { Maximum power output at a speed of } \\
1500 \mathrm{rpm}\end{array}$ & $3.68 \mathrm{~kW}$ \\
\hline $\begin{array}{l}\text { Number of cylinders } \times \text { cylinder } \\
\text { position } \times \text { stroke }\end{array}$ & One $\times$ Vertical position $\times$ four-stroke \\
\hline Bore $\times$ stroke & $80 \mathrm{~mm} \times 110 \mathrm{~mm}$ \\
\hline Method of cooling & Water cooled \\
\hline Rated speed ( constant) & $1500 \mathrm{rpm}$ \\
\hline Fuel injection system & In-line and direct injection \\
\hline Compression ratio & $16: 1$ \\
\hline BMEP @ 1500 rpm & 5.31 bar \\
\hline $\begin{array}{l}\text { Manufacturer's recommended } \\
\text { injection timing and pressure }\end{array}$ & $27^{\circ}$ bTDC $\times 190$ bar \\
\hline Dynamometer & Electrical dynamometer \\
\hline Number of holes of injector and size & Three $\times 0.25$ mm \\
\hline Type of combustion chamber & Direct injection type \\
\hline Fuel injection nozzle & $\begin{array}{l}\text { Make: } \text { MICO-BOSCH } \\
\text { No- 0431-202-120/HB }\end{array}$ \\
\hline Fuel injection pump & Make: BOSCH: NO- $8085587 / 1$ \\
\hline
\end{tabular}

Smoke levels and NOx levels were measured with AVL smoke meter and Netel Chromatograph NOx analyzer respectively at full load operation of the engine. The specification of the measuring instruments were shown in Table. 3

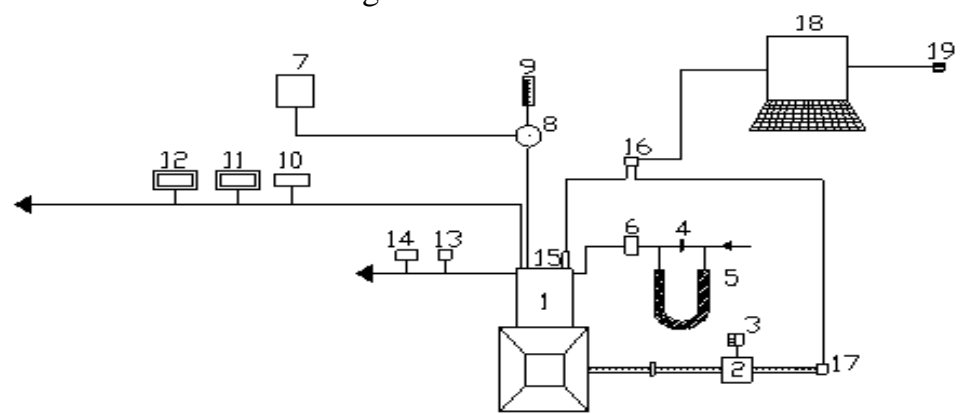

1.Engine, 2.Electical Dynamometer, 3.Load Box, 4.Orifice meter, 5.U-tube water manometer, 6.Air box, 7.Fuel tank, 8, Pre-heater, 9.Burette, 10. Exhaust gas temperature indicator, 11.AVL Smoke meter, 12.Netel Chromatograph NOx Analyzer, 13.Outlet jacket water temperature indicator, 14. Outlet-jacket water flow meter, 15.Piezo-electric pressure transducer, 16.Console, 17.TDC encoder, 18.Pentium Personal Computer and 19. Printer

Fig 1 Experimental Set-up 
Table 3 Specifications of Analyzers

\begin{tabular}{|l|l|l|l|}
\hline Name of the analyzer & Measuring Range & Precision & Resolution \\
\hline AVL Smoke meter & $0-100 \mathrm{HSU}$ & $1 \mathrm{HSU}$ & $1 \mathrm{HSU}$ \\
\hline $\begin{array}{l}\text { Netel Chromatograph } \\
\text { NOx analyzer }\end{array}$ & $0-2000 \mathrm{ppm}$ & $2 \mathrm{ppm}$ & $1 \mathrm{ppm}$ \\
\hline
\end{tabular}

Different operating conditions of the biodiesel were normal temperature and preheated temperature. Different injector opening pressures attempted in this experimentation were 190 bar, 230 bar and 270 bar. Various injection timings attempted in the investigations were $27-34^{\circ} \mathrm{bTDC}$.

\section{Definitions of used values:}

Brake thermal efficiency (BTE); It is the ratio of brake power of the engine to the energy supplied to the engine. Brake power was measured with dynamometer. Energy supplied to the engine is the product of rate of fuel consumed $\left(\mathrm{m}_{\mathrm{f}}\right)$ and calorific value $\left(c_{v}\right)$ of the fuel. Higher the efficiency better the performance of the engine is.

$$
B T E=\frac{B P}{m_{f \times C V}}
$$

Brake Mean Effective Pressure (BMEP) It is defined as specific torque that is torque per unit volume. Its unit is bar.

$$
\mathrm{BP}=\frac{B M E P \times 10^{5} \times L \times A \times n \times k}{60000}
$$

$\mathrm{BP}=\mathrm{Brake}$ power of the engine in $\mathrm{kW}$

$\mathrm{BMEP}=\mathrm{Brake}$ mean effective pressure of the engine in bar

$\mathrm{L}=$ Stroke of the engine $=110 \mathrm{~mm}$

$\mathrm{D}=$ Bore of the cylinder $=80 \mathrm{~mm}$

$\mathrm{n}=$ Power cycles per minute $=\mathrm{N} / 2$, where $\mathrm{N}=$ Speed of the engine $=1500 \mathrm{rpm}$

$\mathrm{k}=$ Number of cylinders $=01$

HSU $=$ Hartridge smoke unit. Higher the value, higher the concentration of carbon particles.

\section{RESULTS AND DICUSSION}

Results and discussion were made in three parts such as 1 . Determining optimum injection timing with $\mathrm{CE}$ and engine with LHR combustion chamber, 2) Determining the exhaust emissions.

\subsection{Exhaust Emissions}

This section deals with i) effect of smoke and NOx emissions on human health and its impact on environment, ii) Comparative study of smoke and NOx emissions in CE and engine with LHR combustion chamber with varied injector opening pressure and injection timing with different operating conditions of the vegetable oil.
Smoke and NOx are the emissions from diesel engine cause [34] health hazards like inhaling of these pollutants cause severe headache, tuberculosis, lung cancer, nausea, respiratory problems, skin cancer, hemorrhage, etc. The contaminated air containing carbon dioxide released from automobiles reaches ocean in the form of acid rain, there by polluting water. Hence control of these emissions is an immediate task and important. Figure 2 denotes that smoke levels increased by $25 \%$ and $13 \%$ with engine with LHR combustion chamber with pure diesel operation at recommended and optimized injection timings respectively in comparison with conventional engine.

This was due to fuel cracking at higher temperature, leading to increase in smoke density. Higher temperature of engine with LHR combustion chamber produced increased rates of both soot formation and burn up. The reduction in volumetric efficiency [34] and air-fuel ratio [34] was responsible factors for increasing smoke levels in the LHR engine near the peak load operation of the engine. As expected, smoke increased in the LHR engine because of higher temperatures and improper utilization of the fuel consequent upon predominant diffusion combustion [35].

When injection timing was advanced to their respective optimum values with both versions of the engine, smoke levels decreased with diesel operation. This was due to increase of air fuel ratios, causing effective combustion in both versions of the engine. The reason for reduction of smoke levels in the LHR engine was reduction of gas temperatures, with the availability of more of oxygen when the injection timing was advanced to its optimum value. This was confirmed by the observation of improved air fuel ratios [34] with the increase of injector opening pressure and with the advancing of the injection timing with both versions of the combustion chamber. However at optimum injection timings, smoke levels were lower in the conventional engine compared to the engine with LHR combustion chamber, due to improved air fuel ratios [34] and volumetric efficiency in the conventional engine.

Smoke levels decreased by $28 \%$ and $22 \%$ with engine with LHR combustion chamber with biodiesel operation at recommended and optimized injection timings respectively in comparison with conventional engine. Engine with LHR combustion chamber marginally reduced smoke levels due to efficient combustion and less amount of fuel accumulation on the hot combustion chamber walls of the LHR combustion chamber at different operating conditions of the biodiesel compared to the conventional engine 
Conventional engine with pure diesel operation gave lower smoke levels in comparison with biodiesel. This was due to the higher value of ratio of $\mathrm{C} / \mathrm{H}$ [ C57H9806], (C= Number of carbon atoms and $\mathrm{H}=$ Number of hydrogen atoms in fuel composition ( higher the value of this ratio means, number of carbon atoms are higher leading to produce more carbon dioxide and more carbon monoxide and hence higher smoke levels) of fuel composition. The increase of smoke levels was also due to decrease of air-fuel ratios [35] and volumetric efficiency [35] with biodiesel compared with pure diesel operation. Smoke levels were related to the density of the fuel. Since biodiesel has higher density compared to diesel fuel, smoke levels were higher with biodiesel.

Smoke levels decreased [35] at the respective optimum injection timing with test fuels. This was due to initiation of combustion at early period. This was due to increase of air entrainment, at the advanced injection timings, causing lower smoke levels.
Smoke levels were found to be lower with biodiesel operation compared with diesel operation with engine with LHR combustion chamber. The inherent oxygen of biodiesel might have provided some useful interactions between air and fuel, particularly in the fuel-rich region. Certainly, it is evident proof of the oxygen content of biodiesels enhanced the oxidation of hydrocarbon reactions thus reducing smoke levels.

The data from Table 4 shows a decrease in smoke levels with increase of injector opening pressure, with different operating conditions of the biodiesel.

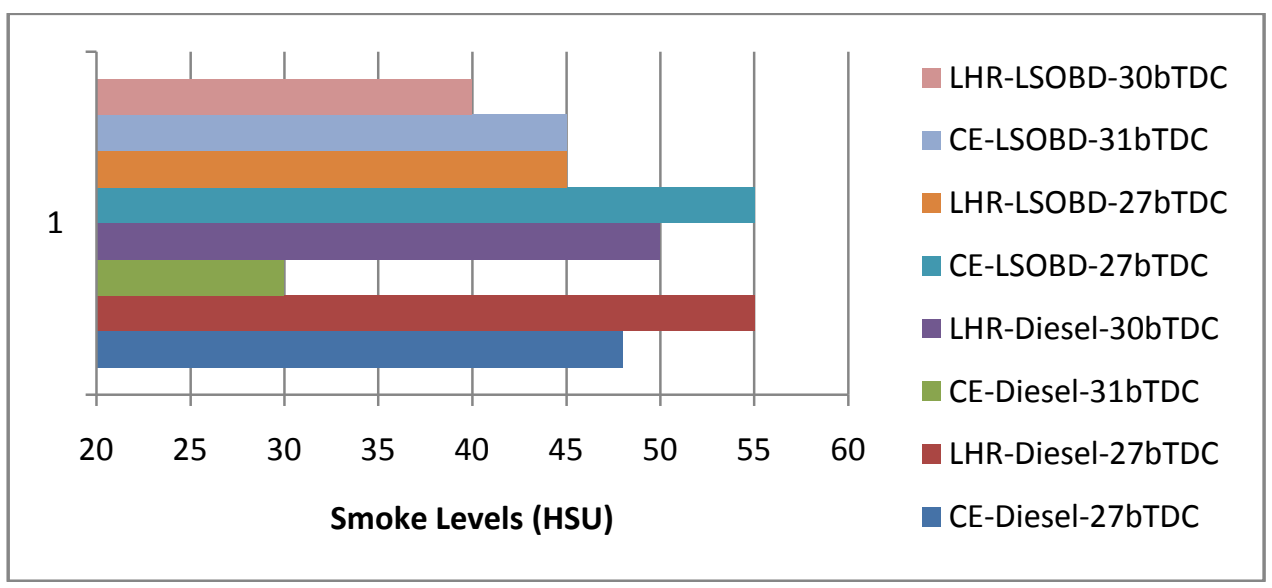

Fig 2 Bar charts showing the variation of smoke levels in Hartridge smoke unit (HSU) at peak load operation with test fuels at recommended and optimized injection timings at an injector opening pressure of 190 bar at full load operation.

This was due to improvement in the fuel spray characteristics at higher injector opening pressure causing lower smoke levels. Even though viscosity of biodiesel was higher than diesel, high injector opening pressure improves spray characteristics, hence leading to a shorter physical delay period. The improved spray also leads to better mixing of fuel and air resulting in turn in fast combustion. This will enhance the performance [35]

Preheating of the biodiesel reduced smoke levels, when compared with normal temperature of the biodiesel. This was due to i) the reduction of density of the biodiesel, as density was directly related to smoke levels, ii) the reduction of the diffusion combustion proportion with the preheated biodiesel, iii) the reduction of the viscosity of the biodiesel with which the fuel spray does not impinge on the combustion chamber walls of lower temperatures rather than it directed into the combustion chamber.
NOx are the precursor pollutants which can combine to form photochemical smog. These irritate the eyes and throat, reduces the ability of blood to carry oxygen to the brain and can cause headaches, and pass deep into the lungs causing respiratory problems for the human beings. Long-term exposure has been linked with leukemia. Therefore, the major challenge for the existing and future diesel engines is meeting the very tough emission targets at affordable cost, while improving fuel economy.

Temperature and availability of oxygen are two favorable conditions to form NOx levels. At peak load, NOx levels increased with test fuels at recommended injection timing due to higher peak pressures, temperatures as larger regions of gas burned at close-to-stoichiometric ratios. 
Figure 3 denotes that NOx levels increased by $41 \%$ and $5 \%$ with engine with LHR combustion chamber with pure diesel operation at recommended and optimized injection timings respectively in comparison with conventional engine. At peak load operation, due to the reduction of air fuel ratio with engine with LHR combustion chamber, which was approaching to the stoichiometric ratio, causing more NOx concentrations as combustion chamber was maintained more hot due to the insulating parts.

NOx levels increased by $29 \%$ and $9 \%$ with engine with LHR combustion chamber with biodiesel operation at recommended and optimized injection timings respectively in comparison with conventional engine. Increase of combustion temperatures [35] with the faster combustion and improved heat release rates [35] in the LHR engine cause higher NOx levels in comparison with conventional engine with biodiesel operation.

From the Table.4, it was observed that Increasing the injection advance resulted in higher combustion temperatures and increase of resident time leading to produce more NOx concentration in the exhaust of conventional engine with test fuels.

At the optimum injection timing, the LHR engine with test fuels produced lower NOx emissions, at peak load operation compared to the same version of the engine at the recommended injection timing. This was due to decrease of combustion temperatures[36] with improved air fuel ratios.

Table.4 Data of exhaust emissions at peak load operation

\begin{tabular}{|c|c|c|c|c|c|c|c|c|c|c|c|c|c|}
\hline \multirow{4}{*}{$\begin{array}{l}\text { Injection } \\
\text { Timing } \\
\left({ }^{\circ} \text { bTDC }\right)\end{array}$} & \multirow{4}{*}{ Test Fuel } & \multicolumn{6}{|c|}{ Smoke Levels (Hartridge Smoke Unit) } & \multicolumn{6}{|c|}{ NOx Levels(ppm) } \\
\hline & & \multicolumn{6}{|c|}{ Injector Opening Pressure (Bar) } & \multicolumn{6}{|c|}{ Injector Opening Pressure (Bar) } \\
\hline & & \multicolumn{2}{|c|}{190} & \multicolumn{2}{|c|}{230} & \multicolumn{2}{|c|}{270} & \multicolumn{2}{|c|}{190} & \multicolumn{2}{|c|}{230} & \multicolumn{2}{|c|}{270} \\
\hline & & NT & PT & NT & PT & NT & PT & NT & PT & NT & PT & NT & PT \\
\hline \multirow{2}{*}{ 27(CE) } & $\mathrm{DF}$ & 48 & -- & 38 & -- & 34 & - & 850 & --- & 900 & ---- & 950 & --- \\
\hline & LSOBD & 55 & 50 & 50 & 45 & 45 & 40 & 950 & 875 & 1000 & 925 & 1050 & 975 \\
\hline \multirow{2}{*}{ 27LHR) } & $\mathrm{DF}$ & 55 & -- & 50 & -- & 45 & -- & 1100 & -- & 1050 & -- & 1000 & -- \\
\hline & LSOBD & 45 & 40 & 40 & 35 & 35 & 30 & 1225 & 1175 & 1175 & 1125 & 1125 & 1075 \\
\hline \multirow[b]{2}{*}{ 30(LHR) } & LSOBD & 40 & 35 & 35 & 30 & 30 & 25 & 1175 & 1125 & 1125 & 1075 & 1075 & 1025 \\
\hline & $\mathrm{DF}$ & 50 & -- & 45 & -- & 40 & -- & 1050 & -- & 1000 & -- & 950 & -- \\
\hline \multirow{2}{*}{$31(\mathrm{CE})$} & $\mathrm{DF}$ & 30 & -- & 30 & -- & 35 & -- & 1100 & -- & 1150 & -- & 1200 & -- \\
\hline & LSOBD & 45 & 40 & 40 & 35 & 35 & 30 & 1150 & 1100 & 1200 & 1150 & 1250 & 1200 \\
\hline
\end{tabular}

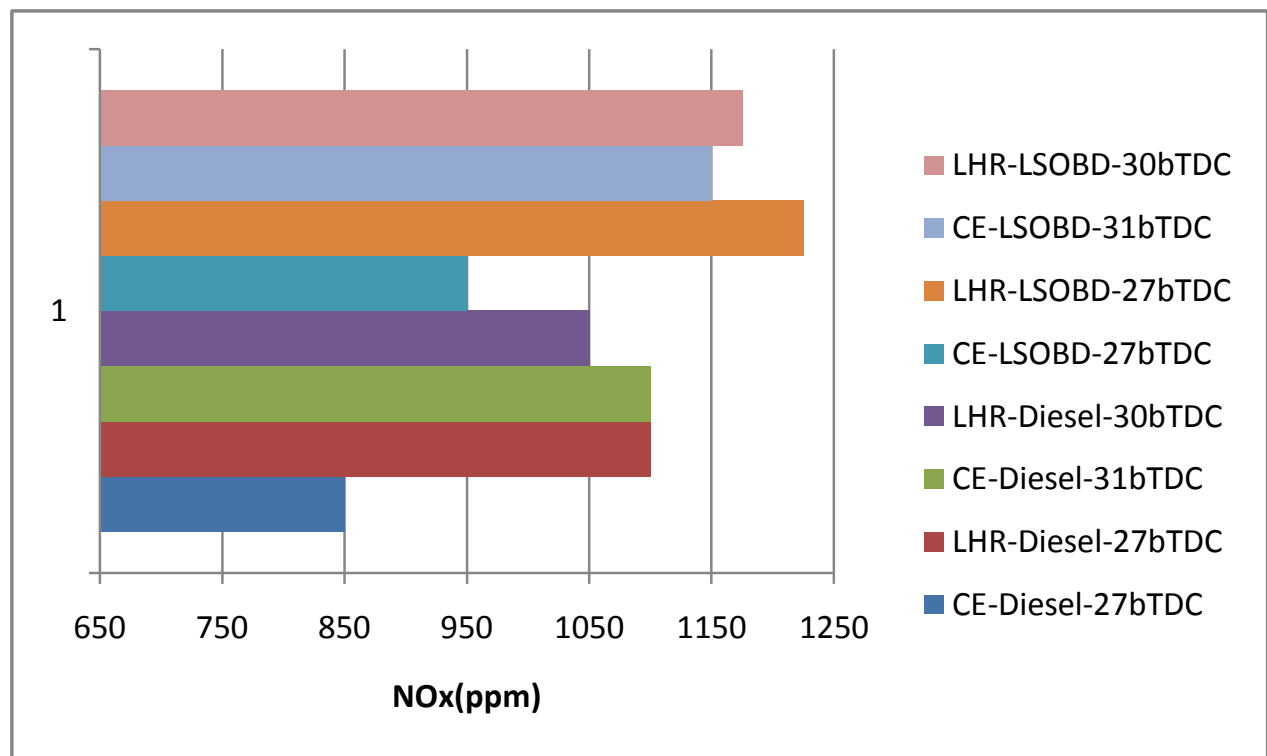

Fig 3 Bar charts showing the variation of NOx levels at peak load operation with test fuels at recommended and optimized injection timings at an injector opening pressure of 190 bar at full load operation

Biodiesel with both versions of the engine gave higher NOx levels than pure diesel operation. The linseed oil based biodiesel having long carbon chain $\left(\mathrm{C}_{20}-\mathrm{C}_{32}\right)[31]$ recorded more NOx than that of fossil diesel having both medium $\left(\mathrm{C}_{8^{-}}\right.$ $\left.\mathrm{C}_{14}\right)$ as well as long chain $\left(\mathrm{C}_{16}-\mathrm{C}_{28}\right)$. The increase in NOx emission might be an inherent characteristic of biodiesel due 
to the presence of $54.9 \%$ of mono-unsaturated fatty acids(MUFA) and $18 \%$ of poly-unsaturated fatty acids (PUFA). That means, the long chain unsaturated fatty acids (MUFA and FUPA) such as oleic C18:1 and linoliec C18:2 fatty acids are mainly responsible for higher levels of NOx emission [33]. Another reason for higher NOx levels is the oxygen (10\%) present in the methyl ester. The presence of oxygen in normal biodiesel leads to improvement in oxidation of the nitrogen available during combustion. This will raise the combustion bulk temperature responsible for thermal NOx formation. Many researchers reported that oxygen [33] and nitrogen [35] content of biodiesel can cause an increase in NO $x$ emissions. The production of higher NOx with biodiesel fueling is also attributable to an inadvertent advance of fuel injection timing due to higher bulk modulus of compressibility, with the in-line fuel injection system.

From the Table 4, it is noted that these levels increased with increase of injector opening pressure with different operating conditions of biodiesel. NOx slightly increased with test fuels as injector opening pressure increased. As seen from the Table.4, that peak brake thermal efficiency increased as injector opening pressure increased. The increase in peak brake thermal efficiency was proportional to increase in injector opening pressure. Normally, improved combustion causes higher peak brake thermal efficiency due to higher combustion chamber pressure [35] and temperature and leads to higher NOx formation. This is an evident proof of enhanced spray characteristics, thus improving fuel air mixture preparation and evaporation process.

NOx levels decreased with preheating of the biodiesel as noticed from the Table.4. The fuel spray properties may be altered due to differences in viscosity and surface tension. The spray properties affected may include droplet size, droplet momentum, degree of mixing, penetration, and evaporation. The change in any of these properties may lead to different relative duration of premixed and diffusive combustion regimes. Since the two burning processes (premixed and diffused) have different emission formation characteristics, the change in spray properties due to preheating of the vegetable oil (s) are lead to reduction in NOx formation. As fuel temperature increased, there was an improvement in the ignition quality, which will cause shortening of ignition delay. A short ignition delay period lowers the peak combustion temperature which suppresses NOx formation [33,35]. Lower levels of NOx is also attributed to retarded injection, improved evaporation, and well mixing of preheated biodiesel due to their viscosity at preheated temperatures. Biodiesel has higher value of NOx emissions followed by diesel. This was because of inherent nature of biodiesel as it has oxygen molecule in its composition.

\subsection{Research Findings and Suggestions}

Investigations on study of exhaust emissions and combustion characteristics with engine with ceramic coated LHR combustion were systematically carried out with varied injector opening pressure and injection timing with different operating conditions of the test fuels with various configurations of the combustion chamber. However, engine with LHR combustion chamber increased NOx levels with test fuels and hence study of reduction of NOx emission is necessary. .

\section{REFERNCES}

[1] Matthias Lamping, Thomas Körfer, Thorsten Schnorbus, Stefan Pischinger, Yunji Chen : Tomorrows Diesel Fuel Diversity - Challenges and Solutions, SAE 2008-01-1731

[2] Agarwal,A.K. (2006). Bio-fuels (alcohols and biodiesel) applications as fuels for internal combustion engines. International Journal Energy Combustion Science, 33,233-271

[3] Babu, A.K. and Devarajane,G. (2003). Vegetable oils and their derivatives as fuels for $\mathrm{CI}$ engines: an overview.SAE Paper No.2003-01-0767.

[4] Surendra, R,K., Suhash, D.V. (2008). Jatropha and karanj bio-fuel: as alternate fuel for diesel engine. ARPN Journal of Engineering and Applied Sci, 3(1).

[5] Devan, P.K. and Mahalakshmi, N.V. (2009). Performance, emission and combustion characteristics of poon oil and its blends in a DI diesel engine. Fuel, 88,861-870.

[6] Misra, R.D., Murthy, M.S.(2010). Straight vegetable oils usage in a compression ignition engine-A review. Renewable and Sustainable Energy Reviews, ISSN: 1364-0321. 14, 3005-3013.

[7] Bari, S., Lim, T.H.,Yu, C.W.(2002).Effect of preheating of crude palm oil on injection system, performance and emission of a diesel engine. Renewable Energy, 27(3), 339-351.

[8] Agarwal, D., Agarwal, A.K. (2007).Performance and emissions characteristics of jatropha oil (preheated and blends) in a direct injection compression ignition engine. Int. J. Applied Thermal Engineering, 27, $2314-$ 23.

[9] Canakei, M. (2005).Performance and emission characteristics of biodiesel from soyabeen oil. Proc. I Mech E, Part-D, Journal of Automobile Engineering, 219, 915-922.

[10] Jiwak Suryawanshi, (2006), Performance and emission characteristics of $\mathrm{CI}$ engine fueled by coconut oil methyl ester, SAE Paper No. 2006-32-0077.

[11] Marek Tatur, Harsha Nanjundaswamy, Dean Tomazic, Matthew Thornton. (2008). Effects of Biodiesel Operation on Light-Duty Tier 2 Engine and Emission Control Systems, SAE 2008-01-0080 
[12] Murugesan, A., Umarani, C., Subramanian,R., Nedunchezhian, N. (2009).Bio-diesel as an alternate fuel for diesel engines. Renewable and Sustainable Energy Reviews, 13(3), 653-662.

[13] Venkatramn. And Devaradjane, G. (2010). Experimental investigation of performance and emission characteristics of diesel-pungam oil, methyl esters diesel blends fueled DI engine at optimum engine operating parameters. International Journal of Green energy and env, 1, 7-12.

[14] Heywood, J.B. (1988). Fundamentals of Internal Combustion Engines. Tata McGraw Hills, New York.

[15] Celikten, I. (2003). An experimental investigation of the effect of the injection pressure on the engine performance and exhaust emission in indirect injection diesel engines. Applied Thermal Engineering, 23, 2051-2060.

[16] Cingur, Y., \& Altiparmak, D. (2003). Effect of cetane number and injection pressure on a DI diesel engine performance and emissions. Energy Conversion and Management, 44, 389-397.

[17] Hountalas, D.T., Kouremenos, D.A., Binder, K.B., Schwarz, V., \& Mavropoulos, G.C. (2003). Effect of injection pressure on the performance and exhaust emissions of a heavy duty DI diesel engine, SAE Technical Paper No. 2003-01-0340. Warrendale, PA.

[18] Venkanna, B.K., \& Venkataramana, R.C. (2010). Influence of fuel injection rate on the performance, emission and combustion characteristics of DI diesel engine running on calophyllum inophyllum linn oil (honne oil)/diesel fuel blend, SAE Technical Paper No. 2010-01-1961.

[19] Chandrakasan Solaimuthu and Palani Swamy Govindaraju (2012). Effect of injection timing on performance, combustion and emission characteristics of diesel engine using mahua oil methyl ester. Journal of Scientific and Industrial Research, 71, 69-74.

[20] Venkateswara Rao, N., Murali Krishna, M.V.S. and Murthy, P.V.K. (2013). Effect of injector opening pressure and injection timing on performance parameters of high grade low heat rejection diesel engine with tobacco seed oil based biodiesel. International Journal of Current Engineering \& Technology, ISSN: 2277-4106,3(4),1401-1411

[21] Venkateswara Rao, N., Murali Krishna, M.V.S. and Murthy, P.V.K. (2013). Investigations on performance parameters of ceramic coated diesel engine with tobacco seed oil biodiesel International Journal of Engineering and Technology, ISSN: 2231-1963, 6(5),2286-2300

[22] Venkateswara Rao, N., Murali Krishna, M.V.S. and Murthy, P.V.K. (2013). Comparative studies on exhaust emissions and combustion characteristics of ceramic coated diesel engine with tobacco seed oil based biodiesel, International Journal of Advanced
Scientific \& Technical Research, 3(5), ISSN: 22499954,3(5),334-349

[23] Parlak, A., Yasar, H., ldogan O. (2005).The effect of thermal barrier coating on a turbocharged Diesel engine performance and exergy potential of the exhaust gas. Energy Conversion and Management, ISSN: 0196-8904, 46(3), 489-499.

[24] Ekrem, B., Tahsin, E., Muhammet, C. (2006). Effects of thermal barrier coating on gas emissions and performance of a LHR engine with different injection timings and valve adjustments. Journal of Energy Conversion and Management, ISSN: 0196-8904, 47,1298-1310.

[25] Ciniviz, M., Hasimoglu, C., Sahin, F., Salman, M. S. (2008). Impact of thermal barrier coating application on the performance and emissions of a turbocharged diesel engine. Proceedings of The Institution of Mechanical Engineers Part D-Journal Of Automobile Eng,222 (D12), ISSN: : 0954-4070, 2447-2455

[26] Murali Krishna, M.V.S., Chowdary, R.P., Reddy, T.K.K. and Murthy,P.V.K.. (2012). Performance evaluation of waste fried vegetable oil in la low grade low heat rejection diesel engine. International Journal of Research in Mechanical Engineering and Technology, ISSN : 2249-5770, 2(2), 35-43.

[27] Kesava Reddy, Ch., Murali Krishna, M.V.S., Murthy, P.V.K. and Ratna Reddy,T. (2012).Performance evaluation of a low grade low heat rejection diesel engine with crude jatropha oil. International Scholarly Research Network (ISRN) Renewable Energy (USA), ISSN: 2090-7451, 2012, Article ID 489605, 1-10.

[28] Ratna Reddy, T., Murali Krishna, M.V.S., Kesava Reddy, Ch. and Murthy, P.V.K. (2012). Comparative performance of ceramic coated diesel engine with mohr oil in crude and biodiesel form. International Journal of Engineering and Advanced Technology, (CSIR), ISSN: 2249-8958, 2(3), 588-596.

[29] Varma, Mahesh, N and Giridhar (2010). Synthesis of Biodiesel from Castor Oil and Linseed Oil in Supercritical Fluids, Industrial and Engineering Chemistry Research, Division of Mechanical Sciences, and Chemical Engineering.

[30] Tapasvi D, Wiesenborn D, Gustafson C (2005). Process Model for Biodiesel Production from various Feedstock's, Trans. ASAE, 48(6): 2215- 2221.

[31] Jindal S, Bhagwati PN, Narendra SR (2010). Comparative Evaluation of Combustion, Performance and Emissions of Jatropha Methyl Ester and Karanja Methyl Ester in a Direct Injection Diesel Engine, Energy Fuels, 24: 1565-1572.

[32] Murali Krishna, M.V.S. (2004). Performance evaluation of low heat rejection diesel engine with alternate fuels. PhD Thesis, J.N.T. University, Hyderabad

[33] Rao, P.V. (2011). Effect of properties of Karanja methyl ester on combustion and NOx emissions of a 
diesel engine. Journal of Petroleum Technology and Alternative Fuels Vol. 2(5), 63-75.

[34] Gattamaneni, L.N., Saravanan, S., Santhanam, S. and Kuderu, R. (2008). Combustion and emission characteristics of diesel engine fuelled with rice bran oil methyl ester and its diesel blends. Thermal Science, 12, 139-150.

[35] Yamane K, Ueta A, Shimamoto Y (2001). Influence of Physical and Chemical Properties of Biodiesel Fuel on Injection, Combustion and Exhaust Emission Characteristics in a DI-CI Engine. Tran. Of the Jap. Soc. Mech. Eng., 32(2): 25-30. 